\title{
The Feeding Tube- a Simple Yet Handy Aid to Intubate an Unanticipated Difficult Pediatric Airway
}

\author{
Suma Mary Thampi, ${ }^{1}$ Serina Ruth Salins, ${ }^{1}$ Divya P Jacob, ${ }^{1}$ Ahwad Sheetal Avinash' \\ 'Department of Anesthesia, Christian Medical College Hospital, Vellore.
}

\section{ABSTRACT}

Pediatric intubation requires certain unique set of additional skills compared to intubating adults. The challenges of successfully intubation of a child increases as the age and size of the child decrease and are compounded when airway difficulties arise for various reasons. Often in the rural setting, such procedures may have to be carried out by health care personnel who get trained on-the-job, and in the absence of adequate technological back-up. This leads to an increased incidence of failed intubations which can have devastating complications, especially in the pediatric age group. We describe a simple technique which helped us while intubate a 40-day old infant, without any major catastrophes.

Keywords: airway management; infant; newborn; intubation; endotracheal.

\section{INTRODUCTION}

Neonatal and pediatric intubation is very different from intubating an adult, no matter how trained the health care personnel maybe in adult resuscitation, because of the fundamental anatomical and physiological differences. ${ }^{1}$ Although usually catered to by pediatric anesthetists or intensivists, lesser experienced personnel maybe called upon, during resuscitation in emergency departments or labour rooms in primary or secondary care hospitals. In many parts of the developing world, pediatric care is administered by 'non-pediatric, on-the-job-trained personnel', even in pediatric intensive care units and in field of anaesthesia. ${ }^{2}$ Therefore, assessment and anticipation of potentially difficult airway situations may be rather difficult. We describe our experience in intubating an infant with an unanticipated difficult airway, where a simple feeding tube helped in succeeding with the intubation attempt, without any unwanted catastrophes.

\section{CASE REPORT}

A 40 day old baby, born at 31 weeks of gestation, and weighing 2.8 kilograms, presented for reduction of an irreducible left sided inguinal hernia. On general examination he was noted as having a very pointed chin without any other significant dysmorphic features.
He had significant patent ductus arteriosus $(3.9 \mathrm{~mm})$ and a small ventricular septal defect with left to right shunt. General anesthesia was planned with endotracheal intubation, and no additional difficulty in airway management was anticipated except that which accompanies the regular pediatric airway. He was maintained on intravenous dextrose containing fluid while being fasted for the surgery. After establishing adequate monitoring of electrocardiogram, non-invasive blood pressure and a pulse oximeter, anesthesia was induced with $5 \mathrm{mg} / \mathrm{kg}$ Thiopentone and paralyzed with Atracurium $0.5 \mathrm{mg} / \mathrm{kg}$. Intubation was attempted by a senior anesthesia registrar with size 0 Miller blade (Anesthetics India Pvt Ltd.) which revealed a LehaneCormack grade IV laryngoscopy. Mask ventilation was resumed before any drop in oxygen saturation or heart rate. Repeat attempt by a senior consultant anesthetist with size one Miller blade after head repositioning did not improve the view much. However, this time we could visualize a small opening which could not be conclusively determined as either the esophagus or the trachea. At this point, it was decided to pass a six $\mathrm{Fr}$

Correspondence: Dr. Suma Mary Thampi, Department of Anesthesia, Christian Medical College Hospital, Vellore, India. Email: sumadavid@ gmail.com, Phone: +91-416-228-2105. 
nasogastric tube (NGT) down this opening with the plan of either rail-roading an Endotracheal tube (ETT) over it had it reached the tracheo-bronchial tree or using it as a guide to locate the glottic opening if it had passed into the esophagus. On checking its position by auscultation, it was found to have reached the stomach. Through this, the stomach was subsequently decompressed, because by this time it was moderately distended due to gastric insufflation during the repetitive mask ventilation to maintain saturation from falling below $90 \%$. Assuming that the trachea would be anterior to the esophageal opening, a third attempt at laryngoscopy was decided on. On careful inspection, another small slit-like opening was envisioned at two o'clock position in relation to the NGT. A pediatric bougie was inserted into this opening, over which an uncuffed 3.0 size endo-tracheal tube was rail-roaded into the trachea and its position confirmed with end-tidal carbon-di-oxide. Dexamethasone was administered for its anti-edema effects because of multiple attempts at laryngoscopy.

\section{DISCUSSION}

The incidence of difficult intubation in the pediatric population is not well documented in literature. However, some authors have suggested ranges from $0.7-4.7 \% .^{3}$ In out-of hospital or field intubation, the incidence is as high as $30 \% .{ }^{4}$ These difficult airways in this group of patients may arise due to a variety of causes ranging from congenital cranio-facial syndromes and structural abnormalities to inflammatory and neoplastic disorders. A good number of them may be unexpectedly encountered in an emergency situation either due to inadequate airway evaluation or more commonly, due to the absence of accurate predictors of a difficult airway in this age group. Some of them can even crop up in the face of a seemingly undistinguished morphological appearance, as in our case. In adults, clear guidelines exist on assessment of the airway as well as predicting the possibility of a anticipated difficult airway. ${ }^{5}$ In contrast, no clear guidelines exist for airway assessment in children, save the general directive of younger age and facial dysmorphisms being possibly associated with a difficult airway. ${ }^{6}$ Therefore, anticipating a 'difficult to intubate' situation and thus being adequately prepared for the same may be rather easier said than done.
Failed intubation in children can have devastating complications. ${ }^{7}$ The possibility of a failed attempt is higher with lesser experienced personnel attempting intubation in an emergency setting on an unanticipated difficult airway and obtains a grade III or IV LehaneCormack laryngoscopy view. Unless adequately trained to recognize and handle a difficult airway situation, when faced with a Grade III or IV laryngoscopic view, the health care provider tends to persist with repeated attempts in an effort to pass the endotracheal tube through. This leads to traumatic complications such as laceration and bleeding from the oropharynx, laryngeal perforation, and damage to the intrinsic musculature or dislocated arytenoids. All of these can further worsen an already compromised situation and have devastating implications to the outcome in the patient.

Adding to the problem of facing a difficult pediatric intubation, is often the lack of advanced airway gadgets and technology in the peripheral setting. Gadgets like light wands, video-laryngoscope and fibreoptic bronchoscope are considered as the next step to help intubate a difficult airway. However, they are usually not easily available and accessible in the rural scenario, because of the cost involved in procurement as well as maintenance of these devices. Besides, their use is demanding in the very small age group and needs experienced hands, else these may actually prove counter-productive by adding to the airway damage. ${ }^{8}$ Even though it is advised that a difficult intubation in a child should be undertaken by the most experienced personnel available, often the available person in the scene may not be adequately trained in this aspect of pediatric intubation.

As we described, a feeding tube in position in the esophagus can serve as a visual guide to searching for the glottic opening in a situation faced with a grade three or four laryngoscopy. Rather than persist in further attempts blindly, presence of such a guide can help in a focused search of the area and avoid the possibility of trauma and ensuing failed intubation, which can subsequently have catastrophic implications in children. Keeping in mind such simple handy tips, can serve well in avoiding significant complications in a difficult situation.

\section{REFERENCES}

1. Harless J, Ramaiah R, Bhananker SM. Pediatric airway management. InterJCrit Illn Inj Sci. 2014;4:65-70.

2. Hodges SC, Mijumbi C, Okello M, McCormick BA, Walker IA, Wilson IH. Anaesthesia services in developing countries: defining the problems. Anaesthesia. 2007;62:4-11.
3. Mirghassemi A, Soltani AE, Abtahi M. Evaluation of laryngoscopic views and related influencing factors in a pediatric population. Paediatr Anaesth. 2011;21:663-7.

4. Ehrlich PF, Seidman PS, Atallah O, Haque A, Helmkamp J. Endotracheal intubations in rural pediatric trauma patients. J Pediatr Surg. 2004;39:1376-80. 
5. Gupta S, Sharma R, Jain D. Airway assessment: Predictors of difficult airway. Indian J Anaesth.2005;49:257-62.

6. Heinrich S, Birkholz T, Ihmsen H, Irouschek A, Ackermann A, et al.. Incidence and predictors of difficult laryngoscopy in 11,219 pediatric anesthesia procedures. Paediatr Anaesth. 2012;22:729-36.
7. Divatia JV, Bhowmick K. Complications of endotracheal intubation and other airway management procedures. Indian J Anaesth. 2005;49:308-18.

8. Iacovidou N, Bassiakou E, Stroumpoulis K, Koudouna E, Aroni F, Papalois A, et al. Conventional direct laryngoscopy versus videolaryngoscopy with the GlideScope: a neonatal manikin study with inexperienced intubators. Am J Perinatol. 2011;28:201-6. 